Biochimica et Biophysica Acta, 452 (1976) 335-344

(c) Elsevier/North-Holland Biomedical Press

BBA 67984

\title{
DETERMINATION OF THE REDOX POTENTIAL OF DEAZARIBOFLAVIN BY EQUILIBRATION WITH FLAVINS
}

\author{
MARIAN T. STANKOVICH and VINCENT MASSEY \\ The Department of Biological Chemistry, The University of Michigan, Ann Arbor, Mich. \\ 48109 (U.S.A.)
}

(Received May 17th, 1976)

\section{Summary}

The redox potential of deazariboflavin has been determined for $\mathrm{pH}$ values from 5.5 to 9.2 by equilibration with riboflavin and lumiflavin 3 -acetate. The position of the equilibrium with riboflavin was measured spectrophotometrically and fluorimetrically; the equilibrium potential with lumiflavin 3-acetate was measured spectrophotometrically and potentiometrically. The $E_{\mathrm{m} 7}$ for deazariboflavin was found to be $-0.273 \pm 0.003 \mathrm{~V}$ against the standard hydrogen electrode. Equilibrium with flavodoxin at $\mathrm{pH} 9.5$ and 10.0 was also used to determine the redox potential of deazariboflavin at high $\mathrm{pH}$ values. The $\mathrm{p} K$ of dihydrodeazariboflavin was found from the break in the potential vs. $\mathrm{pH}$ diagram and from spectrophotometric $\mathrm{pH}$ titration. The $\mathrm{pK}$ value obtained by both methods is $7.00 \pm 0.05$. We found that borate, a product of the reducing agent borohydride, complexed with the ribityl sidechain of deazariboflavin, causing a shift in the $\mathrm{pK}$ for the reduced form to values of about 8 .

\section{Introduction}

Deazariboflavin is a compound which has been used frequently as a probe into the mechanism of electron transfer in flavoproteins. Deazaflavins have been bound to the active sites of the apoenzymes of Azotobacter flavodoxin [1], $N$-methylglutamate synthetase [2], D-amino acid oxidase [3-5], Llactate oxidase (ref. 6 and Massey, V., unpublished results), Old Yellow Enzyme (NADPH dehydrogenase) [4,7], glucose oxidase [4] glyoxylate car-

The following abbreviations are used: dR Flox, oxidized 5-deazariboflavin: $d F_{\text {red }} \mathrm{H}_{2}$ and $\mathrm{dFl}_{\mathrm{red}} \mathrm{H}^{-}$, the neutral and anion forms of 1,5-dihydro-5-deazariboflavin; dRFl, 5-deazariboflavin without specification of its oxidation state. Similar abbreviations are employed for riboflavin (RFl), lumiflavin 3-acetate, (LFI) and flavodoxin, (Fl). In the latter case the abbreviation $F^{\circ} H^{\circ}$ is used for the neutral semiquinone species. 
boligase [8] and xanthine oxidase (Massey, V., unpublished results). With these enzymes the deazaflavin binding to the active site showed many of the same characteristics as the binding of normal flavin; a shift of the absorbance maximum, changes in extinction coefficients, and development of distinctive shoulders in the absorption spectrum. In these deazaflavin enzymes, it has been assumed that the deazaflavin uses the normal mechanism of the enzyme to be reduced by the specific substrate. The rates are generally slower by several orders of magnitude than for the normal flavin-containing proteins. The most notable difference is the extremely slow reaction of reduced deazariboflavin with oxygen; the reaction has a $t_{1 / 2}$ of $40 \mathrm{~h}$ compared to ms for reduced flavin. One possible explanation which has been advanced for the difference in reactivity of deazaflavin is based on its apparently low redox potential. Values quoted in the literature differ significantly. In view of the widespread use of deazaflavins as enzyme probes we therefore decided to try to obtain a reliable estimate of the redox potential, and to study its variation with $\mathrm{pH}$. The results of this study are reported here, together with some properties of the reduced form.

\section{Materials and Methods}

Deazariboflavin, dihydrodeazariboflavin, and lumiflavin 3-acetate were the generous gifts of Dr. P. Hemmerich. The $\mathrm{dRFl}_{\mathrm{ox}}$ * was prepared according to the method of Janda and Hemmerich [9], $\mathrm{dRFl}_{\text {red }} \mathrm{H}_{2}$ was obtained from $\mathrm{dRFl}_{\text {ox }}$ by anaerobic treatment with $\mathrm{NaBH}_{4}$ in $50 \%$ aqueous dimethylformamide, from which it precipitates in crystalline state (Janda, M. and Hemmerich, P., personal communication).

Absorbance spectra were recorded with a Cary Model 118 spectrophotometer. Fluorescence emission and excitation spectra were recorded with the ratio-recording fluorimeter similiar to that described by Casola et al. [10]. The Orion Model 701 digital $\mathrm{pH}$ meter was used in potentiometric measurements.

In the experiments where reduced deazariboflavin was equilibrated with riboflavin, lumiflavin 3-acetate or flavodoxin, all manipulations were carried out in the dark. An aliquot of reduced deazaflavin stock solution was added to degassed buffer solution in an anaerobic cuvette with a sidearm; oxidized riboflavin or lumiflavin 3-acetate was stored in the sidearm before addition. After addition of $\mathrm{dRFl}_{\text {red }} \mathrm{H}_{2}$, the cuvette was again made anaerobic. The absorbance spectrum of the $\mathrm{dRFl}_{\text {red }} \mathrm{H}_{2}$ was recorded before $\mathrm{RFl}_{\text {ox }}$ was tipped in, the total deazariboflavin concentration was obtained from the spectrum $\left(\epsilon_{398 \mathrm{dRFI}_{\mathrm{ox}}}=12000 \mathrm{M}^{-1} \cdot \mathrm{cm}^{-1}, \epsilon_{320 \mathrm{dRF}_{\mathrm{red}} \mathrm{H}_{2}}=12800 \mathrm{M}^{-1} \cdot \mathrm{cm}^{-1}\right.$, $\left.\epsilon_{320 \mathrm{RF}_{1} 1_{\mathrm{red}} \mathrm{H}^{-}}=12000 \mathrm{M}^{-1} \cdot \mathrm{cm}^{-1}\right)$. Flavin was tipped in and equilibrium was attained in the thermostatically temperature-regulated $\left(T=25^{\circ} \mathrm{C}\right)$ spectrophotometric compartment. The absorbance spectrum and fluorescence spectra of the equilibrated system were then recorded. The equilibrium concentration of $\mathrm{RFl}_{\text {ox }}$ was determined from the excitation fluorescence spectrum at $450 \mathrm{~nm}$, taken at the emission wavelength of $520 \mathrm{~nm}\left(T=25^{\circ} \mathrm{C}\right)$. The reading was

\footnotetext{
* See footnote $\mathbf{p} 335$.
} 
corrected for $\mathrm{dRFl}_{\mathrm{ox}}$ fluorescence which made a $5-10 \%$ contribution to the emission at $520 \mathrm{~nm}$. The equilibrium concentration of oxidized deazaflavin was taken from the $398-\mathrm{nm}$ spectrophotometric reading. The $A_{398}$ reading was corrected for absorbance due to oxidized $\left(\epsilon=7200 \mathrm{M}^{-1} \cdot \mathrm{cm}^{-1}\right)$ and reduced $\left(\epsilon=2500 \mathrm{M}^{-1} \cdot \mathrm{cm}^{-1}\right)$ riboflavin. The solution was made aerobic and from the final absorbance spectrum, the total riboflavin concentration was measured at $460 \mathrm{~nm}$ where $\mathrm{dRFl} l_{\mathrm{ox}}$ has no absorbance.

Potentiometric measurement of the equilibrated $\mathrm{dRFl}_{\mathrm{red}} \mathrm{H}_{2}$ and lumiflavin 3 -acetate was performed in a anaerobic spectrophotometric cell fitted with a platinum indicator electrode and a saturated calomel reference electrode [11]. Fluorescence measurements were not made on lumiflavin 3 -acetate; concentrations were determined from spectrophotometric measurements.

Flavodoxin from Peptostreptococcus elsdenii was prepared according to the procedure of Mayhew and Massey [12]. The flavodoxin stored in the side-arm of the anaerobic cell was tipped into a solution of $\mathrm{dRFl}_{\mathrm{red}} \mathrm{H}^{-}$in $0.1 \mathrm{M}$ glycine buffer; spectra were recorded from 750 to $300 \mathrm{~nm}$ until equilibrium was reached. The disappearance of the isosbestic point at $490 \mathrm{~nm}$ between the oxidized and semiquinoid forms of flavodoxin indicated the appearance of fully reduced species. Flavodoxin reduction was measured at $460 \mathrm{~nm}$ where the extinction coefficient for oxidized flavodoxin minus semiquinone is 6500 $\mathrm{M}^{-1} \cdot \mathrm{cm}^{-1}$. [12]. When the $\Delta A_{460}$ indicated disappearance of all oxidized flavodoxin, we could be certain that we were measuring the characteristics of the equilibrium between the semiquinone and fully reduced flavodoxin. The concentration of semiquinone could be measured directly from absorbance at 610 or $580 \mathrm{~nm}$. The amount of fully reduced flavodoxin was determined from the difference between the measured total amount of protein (final $A_{460}$ readings of oxidized flavodoxin (aerobic) $\epsilon=9500 \mathrm{M}^{-1} \cdot \mathrm{cm}^{-1}$ and the amount of radical measured at $610 \mathrm{~nm}\left(\epsilon=3900 \mathrm{M}^{-1} \cdot \mathrm{cm}^{-1}\right)$. Flavodoxin was not stable over 3-4-h periods at $\mathrm{pH} 9.5$ and 10 . The amount of flavin mononucleotide dissociated from the protein was measured by fluorescence of the oxygen equilibrated solution. Oxidized flavin mononucleotide is fluorescent; flavin bound to flavodoxin is nonfluorescent. Thus the dissociated flavin mononucleotide could be corrected for. The extent of the correction is $5-10 \%$.

\section{Results}

\section{Effect of light on the air-reoxidation of reduced deazariboflavin}

It has been reported previously that the reoxidation of dihydro-deazaflavins by $\mathrm{O}_{2}$ is an extremely slow process, with $t_{1 / 2}$ values in the range of hours-days $[13,14]$. However, the reaction is very much enhanced by irradiation with visible light; exposure of air-equilibrated solutions of reduced deazaflavin to normal laboratory light for a few minutes results in significant reoxidation. This effect is illustrated in Fig. 1. The course of the reaction is clearly autocatalytic, the rate of the photocatalyzed reoxidation becoming greater as the concentration of oxidized species increases, and reaching a maximum at approximately half-reoxidation. Similar photochemical stimulation of the reaction of reduced deazaflavin with riboflavin and with flavoproteins has 


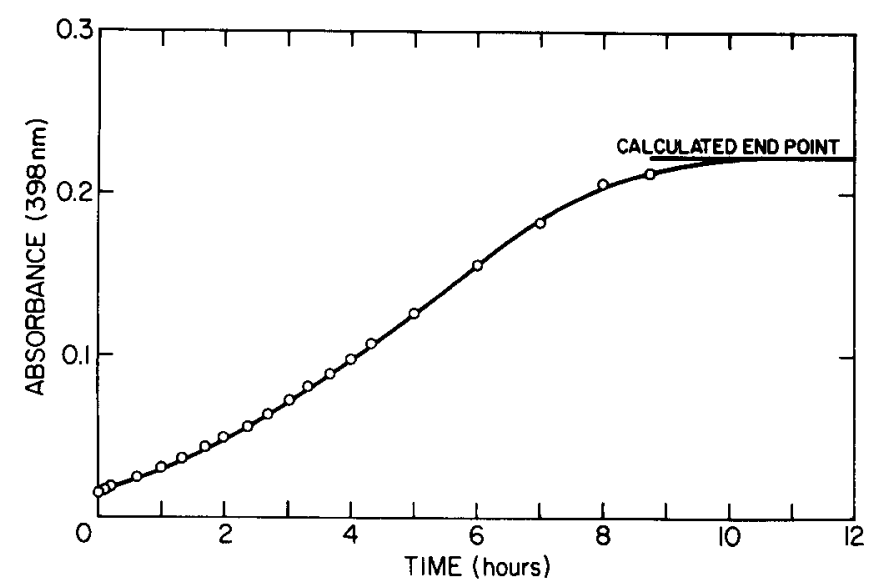

Fig. 1. Progress of light-catalyzed oxidation of reduced deazariboflavin $\left(1.8 \cdot 1 \sigma^{-5} \mathrm{M}\right)$ in air-equilibrated $0.1 \mathrm{M}$ phosphate buffer, pH 7.0. The solid line indicates the calculated end-point of the reaction.

been observed. For this reason all manipulations in the subsequent experiments have been carried out in the dark.

\section{Determination of the redox potential of deazariboflavin}

The redox potential of deazariboflavin at $\mathrm{pH} 7, E_{\mathrm{m} 7}$ was determined to be $-0.273 \pm 0.003 \mathrm{~V}$ against the standard hydrogen electrode. Two types of potentiometric measurements were used to obtain this value. Both types of experiments exploit the fact that there is a comparatively rapid equilibration between oxidized flavin and reduced deazariboflavin. (Massey, V., unpublished results, and ref. 13). In the first type of experiment, reduced deazariboflavin was equilibrated with riboflavin as described in Methods. The concentrations of the species at equilibrium were obtained spectrophotometrically and by fluorescence measurements. The values of the $E_{\mathrm{m}}\left(E^{01}\right)$ potentials for riboflavin have been published for $\mathrm{pH}$ values from 2.52 to 12.9 . [15]. The $E_{\mathrm{m} 7}$ value for $\mathrm{RFl}_{\mathrm{ox}} / \mathrm{RFl}_{\mathrm{red}} \mathrm{H}_{2}$ is $-0.199 \mathrm{~V}$ against the standard hydrogen electrode. Knowing the redox potential for the riboflavin couple and the equilibrium concentrations of dihydro deazariboflavin $\left(\mathrm{dRFl}_{\mathrm{red}} \mathrm{H}_{2}\right)$, deazariboflavin $\left(\mathrm{dRFl} \mathrm{ox}_{\mathrm{ox}}\right), \mathrm{RFl}$ ${ }_{\text {red }} \mathrm{H}_{2}$, and $\mathrm{RFl}_{o x}$, it was therefore possible to calculate the redox potential of the $\mathrm{dRFl} \mathrm{ox}_{\mathrm{ox}} / \mathrm{dRFl} \mathrm{r}_{\mathrm{red}} \mathrm{H}_{2}$ couple using the Nernst equation:

$E_{\mathrm{dRF} 1}^{01}=E_{\mathrm{RF1}}^{01}+\frac{0.059}{n} \log \left(\frac{\left[\mathrm{RF} 1_{\mathrm{ox}}\right]}{\left[\mathrm{RF} 1_{\mathrm{red}} \mathrm{H}_{2}\right]} \cdot \frac{\left[\mathrm{dRF} 1_{\mathrm{red}} \mathrm{H}_{2}\right]}{\left[\mathrm{dRF} 1_{\mathrm{ox}}\right]}\right)$.

The results of these experiments are expressed in the potential vs. $\mathrm{pH}$ curve for the $d R \mathrm{Fl}_{\mathrm{ox}} / \mathrm{dRF} \mathrm{l}_{\text {red }} \mathrm{H}_{2}$ couple in Fig. 2. The ratio of the total RFl to total $\mathrm{dRFl}$ was held as close to unity as possible.

In the second type of redox equilibrium experiment, reduced deazaflavin was equilibrated anaerobically with lumiflavin 3-acetate and the potential of the system was measured with a platinum indicator electrode against a saturated calomel reference electrode. The measurements were made in an 


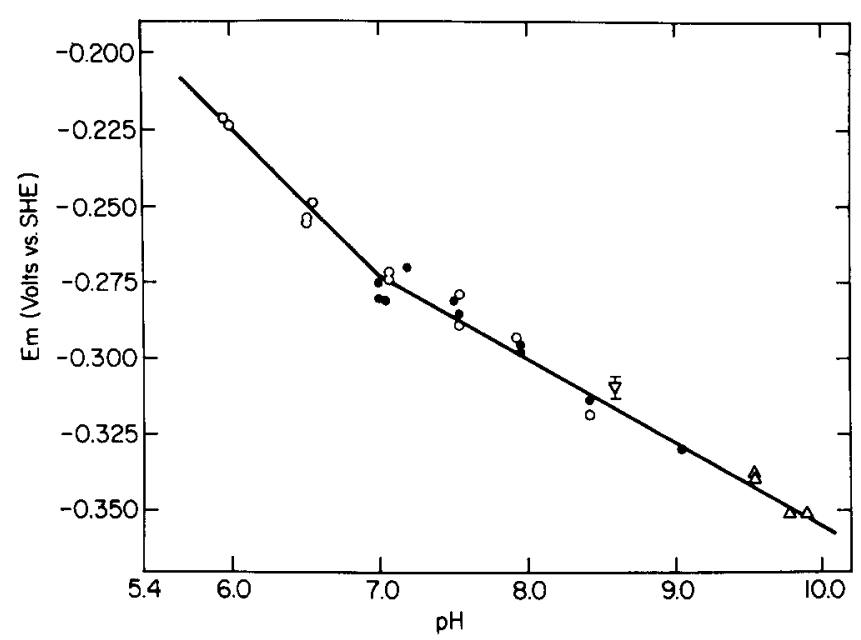

Fig. 2. Potential vs. $\mathrm{pH}$ diagram for $3 \cdot 10^{-5} \mathrm{M}$ deazariboflavin in $0.1 \mathrm{M}$ buffers at $25^{\circ} \mathrm{C}$. $\bigcirc$ indicates equilibrium measurements made with riboflavin, - indicates values obtained from potentiometric measurements with lumiflavin 3 -acetate, $\Delta$ indicates redox potentials determined by equilibration with flavodoxin, $\triangle$ indicates value at pH 8.6 determined by Fisher, Spencer and Walsh [4]. SHE, standard hydrogen electrode.

anaerobic cuvette fitted with the appropriate electrodes as described in Methods [11]. The redox potential was determined as a function of $\mathrm{pH}$. The $\mathrm{dRFl} l_{\text {ox }} / \mathrm{dRFl}_{\text {red }} \mathrm{H}_{2}$ couple was electrochemically inactive at the platinum electrode; the potential of the platinum electrode was independent of the position of the redox equilibrium of the deazaflavin redox couple. Lumiflavin 3 -acetate is electrochemically active at platinum electrodes and it equilibrates relatively rapidly with the deazaflavin molecule. Thus lumiflavin 3 -acetate was added to the reduced deazaflavin to communicate between the deazaflavin and the electrode surface. The $E_{\mathrm{m}}$, for lumiflavin 3 -acetate is $-0.242 \mathrm{~V}$ compared to the standard hydrogen electrode [16], about $30 \mathrm{mV}$ more positive than the deazaflavin couple. A $30-\mathrm{mV}$ difference in redox potential corresponds to an equilibrium constant $K=10$ for $\mathrm{dRFl}_{\text {red }} \mathrm{H}_{2}+\mathrm{LFl}_{\mathrm{ox}} \rightleftharpoons \mathrm{dRFl}$ ox + $\mathrm{LFl}_{\mathrm{red}} \mathrm{H}_{2}$ at $\mathrm{pH}$ 7.0. The equilibrium at lumiflavin 3-acetate and deazaflavin concentration of $3 \cdot 10^{-5} \mathrm{M}$ is well enough poised for the platinum indicator electrode to yield a stable and accurate measurement of the equilibrium cell redox potential. The procedures for the spectropotentiometric measurements with lumiflavin 3 -acetate are identical to those taken for riboflavin, with the exception that fluorescence measurements were not taken; the equilibrium cell potential between the platinum and calomel electrodes was measured potentiometrically. The midpoint potential was calculated from the Nernst equation:

$E_{\text {cell }}=E_{\text {mdRF } 1}+\frac{0.059}{2} \log \frac{\left[\mathrm{dRF} 1_{\text {ox }}\right]}{\left[\mathrm{dRF} 1_{\text {red }} \mathrm{H}_{2}\right]}$.

The values obtained for this type of experiment are also given in Fig. 2. The values for the potential vs. $\mathrm{pH}$ diagrams given by these two methods are identical. 
There was no evidence of long wavelength absorbance at $\lambda=600 \mathrm{~nm}$ indicative of semiquinone formation or charge-transfer complexes for either the lumiflavin acetate or the riboflavin equilibration experiments. The equilibration conditions for the riboflavin experiment were such that the ratio of the total concentrations $R l_{\text {total }} / \mathrm{dRFl}_{\text {total }} \sim 1$. In another set of experiments the $\mathrm{LFl}_{\text {total }} / \mathrm{dRFl}_{\text {total }}$ ratio was varied from 1 to 10 with no change in redox potential at $\mathrm{pH}$ 7.0. This indicated that the equilibrium potential measured was not due to a complex between lumiflavin 3-acetate and dRFI.

A potentiometric dithionite titration of equimolar concentrations of lumiflavin 3-acetate and $\mathrm{dRFl}$ at $\mathrm{pH} 7.0$ yielded an $E_{\mathrm{m} 7}$ for $\mathrm{dRFl}$ of $-0.278 \pm$ $0.007 \mathrm{~V}$ in qualitative agreement with data expressed here.

Determination of redox potentials at high $\mathrm{pH}$ by coupling with flavodoxin The redox characteristics of flavodoxin have been thoroughly studied [12].

$\mathrm{F} 1_{\text {ox }} \underset{\mathrm{E}_{2,7}=-0.115 \mathrm{~V}}{\stackrel{+\mathrm{e}^{-}+\mathrm{H}^{+}}{\longrightarrow}} \mathrm{F} 1 \mathrm{H} \cdot \underset{\mathrm{E}_{1,7}=-0.375 \mathrm{~V}}{\stackrel{+\mathrm{e}^{-}}{\rightleftharpoons}} \mathrm{F} 1_{\text {red }} \mathrm{H}^{-} \underset{\text { pk 5.8 }}{\stackrel{+}{+}} \mathrm{F} 1_{\text {red }} \mathrm{H}_{2}$.

The redox potential for the couple flavodoxin semiquinone/fully reduced flavodoxin is a constant value of $-0.375 \mathrm{~V}$ compared to the standard hydrogen electrode for $\mathrm{pH}$ values greater than 5.8. At $\mathrm{pH}$ values $9.5-10$, the deazaflavin potential extrapolates to values of -0.340 to $-0.355 \mathrm{~V}$; at these high $\mathrm{pH}$ values, the redox potential of the flavoprotein is within $20-35 \mathrm{mv}$ of the values expected for the deazariboflavin couple.

Another way of measuring the redox potential of the dRFl couple was therefore available by equilibration with flavodoxin at $\mathrm{pH}$ values of 9.5-10. The values at $\mathrm{pH} 9.55, E_{\mathrm{m}}=-0.339 \mathrm{~V}$; for $\mathrm{pH} 9.79, E_{\mathrm{m}}=-0.351 \mathrm{~V} ; \mathrm{pH} 9.89$, $E_{\mathrm{m}}=-0.351 \mathrm{~V}$ compared to the standard hydrogen electrode were obtained from flavodoxin equilibrations. As Fig. 2 shows, they agree very well with the extrapolated values obtained for deazaflavin from equilibration with lumiflavin 3 -acetate and riboflavin.

$p K$ of dihydrodeazariboflavin $\left(\mathrm{dRFl}_{\text {red }} \mathrm{H}_{2}\right)$

A pK at pH $7.0 \pm 0.05$ for the reduced form of deazariboflavin is indicated by the break in the potential vs. $\mathrm{pH}$ diagram (fig. 2) at that value. The slope of the potential vs. $\mathrm{pH}$ diagram is $50 \mathrm{mV} / \mathrm{pH}$ unit in the region $5.5-7.0$ and is $27 \mathrm{mV} / \mathrm{pH}$ unit in the region $7.0-9.0$. The time required for equilibration with riboflavin was shorter for $\mathrm{pH}$ values above the $\mathrm{pK} 7.0$ (45 min for $\mathrm{pH}$ $8-8.5)$ and longer at $\mathrm{pH}$ values below the $\mathrm{pK}$ (95 $\mathrm{min}$ for $\mathrm{pH} 5.5-6.5)$.

A second type of experiment was performed to determine the $\mathrm{p} K$ of reduced deazariboflavin. Reduced deazariboflavin $\left(\mathrm{dRFl}_{\mathrm{red}} \mathrm{H}_{2}\right)$, in $0.1 \mathrm{M}$ glycine buffer was tritrated with $3 \mathrm{M}$ acetic acid in an anaerobic spectrophotometric cell fitted with a $\mathrm{pH}$ electrode. Fig. 3 is a spectrophotometric record of the $\mathrm{pH}$ titration. The absorbance at $262 \mathrm{~nm}$ was corrected for dilution and plotted as a function of $\mathrm{pH}$. The resulting graph yielded a $\mathrm{pK}$ of 7.00 for the $\mathrm{pH}$ titration. (Fig. 3 insert). The titration curve shows that $\mathrm{dRFl}_{\text {red }} \mathrm{H}^{-}$has $\lambda_{\max }$ at $319 \mathrm{~nm}$, $\epsilon=12000 \mathrm{M}^{-1} \cdot \mathrm{cm}^{-1}$, and $\mathrm{dRFl}_{\mathrm{red}} \mathrm{H}_{2}$ has $\lambda_{\max }$ at $321 \mathrm{~nm}, \epsilon=12800 \mathrm{M}^{-1}$. $\mathrm{cm}^{-1}$. 


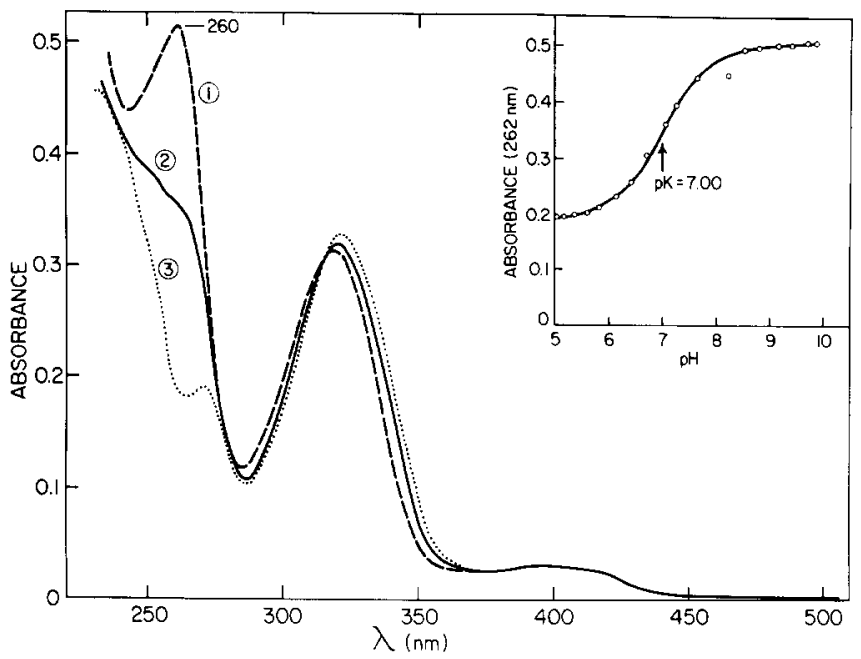

Fig. 3. Anaerobic $\mathrm{pH}$ titration of reduced deazariboflavin in $0.1 \mathrm{M}$ glycine buffer with $3 \mathrm{M}$ acetic acid at $25^{\circ} \mathrm{C}$. Spectra are not corrected for dilution. $1, \mathrm{pH} 9.86 ; 2, \mathrm{pH} 7.04 ; 3, \mathrm{pH} 5.02$. Inset: $A_{262}$ (corrected for dilution) is plotted vs. $\mathrm{pH}$.

The fluorescence emission spectra of $\mathrm{dRFl}_{\text {red }} \mathrm{H}^{-}$and $\mathrm{dRFl}_{\text {red }} \mathrm{H}_{2}$ are shown in Fig. 4. The excitation wavelength is $320 \mathrm{~nm}$; the emission maximum for $\mathrm{dRFl}_{\text {red }} \mathrm{H}^{-}$is $395 \mathrm{~nm}$, for $\mathrm{dRFl}_{\text {red }} \mathrm{H}_{2}$, the emission maximum is $410 \mathrm{~nm}$; the maximum peak height ratio for $\mathrm{dRFl}_{\text {red }} \mathrm{H}_{2} / \mathrm{dFRl}_{\text {red }} \mathrm{H}^{-}$is 0.32 . Fig. $4 \mathrm{c}$ shows that the fluorescence of $\mathrm{dRFl}_{\mathrm{ox}}$ has a maximum at $457 \mathrm{~nm}$; this maximum emission is about 5 times as intense as the $\mathrm{dRFl}_{\text {red }} \mathrm{H}^{-}$fluorescence maximum.

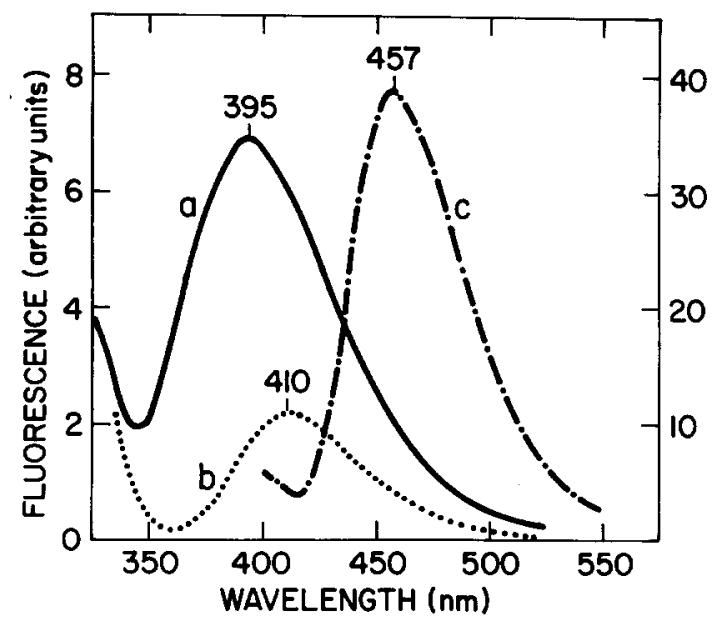

Fig. 4. (a) Fluorescence emission spectrum of anaerobic dRFlred $\mathrm{H}^{-}, 9.8 \cdot 10^{-6} \mathrm{M}, 0.1 \mathrm{M}$ pyrophosphate buffer, pH 8.7 : excitation wavelength is $320 \mathrm{~nm}$. (b) Fluorescence emission spectrum of the same solution titrated to $\mathrm{pH} 5.27$ with $3 \mathrm{M}$ acetic acid; excitation wavelength is $320 \mathrm{~nm}$. (c) Fluorescence emission spectrum of oxidized dRFl, 9.8 $10^{6} \mathrm{M}, 0.1 \mathrm{M}$ phosphate buffer, $\mathrm{pH} 7.0$. Excitation wavelength is 398 $\mathrm{nm}$. The scale on the left is for Figs. a and $b ;$ right scale is for Fig. $c$. 


\section{The effect of borohydride on the $p K$ for deazariboflavin}

In our earlier experiments sodium borohydride was used to reduce the deazariboflavin in situ; approximately $6-9 \mathrm{mg}$ were added to 2-4 $\mathrm{ml}$ of $\mathrm{dRFl}_{\mathrm{ox}}$ stock solution. The reducing agent was left in the deazaflavin solution for 3-5 minutes, then borohydride was destroyed by acidifying the solution to $\mathrm{pH} 5$. The $\mathrm{pH}$ was then adjusted to the desired value. The product of borohydride destruction is borate ion. It is known that borate forms complexes with the ribityl side chain of riboflavin.

Experiments were performed in order to test the effect of borohydride ion and borate ion on the $\mathrm{pK}$ for $\mathrm{dRFl}_{\text {red }} \mathrm{H}_{2}$. We carried out a $\mathrm{pH}$ titration of $\mathrm{dRFl}_{\text {red }} \mathrm{H}_{2}$ (reduced in situ by borohydride) in the presence of borohydride and borate; the titration yielded a $\mathrm{p} K$ value of 8.04 . A pK value of 8.36 was obtained in $0.1 \mathrm{M}$ borate buffer.

\section{Discussion}

Blankenhorn has reported a redox potential for 10-methyl-5-deazaisoalloxazine at $\mathrm{pH} 8.0$ of $-0.380 \mathrm{~V}$ compared to the standard hydrogen eletrode [17]. He obtained this value from the mid-point of a potentiometric reduction wave. In recent studies with a more water-soluble derivative, 10-methyl-3sulfopropyl-5-deazaisoalloxazine he reports a value of $-0.340 \mathrm{~V}$ at $\mathrm{pH} 8.0$ [18]. Fisher, Spencer and Walsh, from determination of the equilibrium constant between NADH and deazariboflavin catalyzed by the NADH-flavin oxidoreductase of Benechea harveyi, calculated the redox potential of the deazaflavin couple to be $-0.310 \pm 0.003 \mathrm{~V}$ at $\mathrm{pH} 8.6$ [4]. Our value at $\mathrm{pH}$ 8.6 is $-0.316 \mathrm{~V}$, in good agreement with their data. The lower value found by Blankenhorn [18] may be a consequence of the negatively charged residue at N-3; lumiflavin 3-acetate has a considerably lower redox potential than lumiflavin or 3-methyllumiflavin [16].

From pH 10 to 7.0 the $E_{o}^{\prime}$ value of the $\mathrm{dRFl} l_{\mathrm{ox}} / \mathrm{dRFl}_{\mathrm{red}} \mathrm{H}_{2}$ couple varies by $0.027 \mathrm{~V}$ per $\mathrm{pH}$ unit. Below $\mathrm{pH} 7.0$ the variation is $0.050 \mathrm{~V}$ per $\mathrm{pH}$ unit, indicating a $\mathrm{p} K$ for the deaza-1,5-dihydroriboflavin of 7.0. Fisher et al. [4] reported a $\mathrm{p} K$ of 7.2 , from spectrophotometric titrations. We have also determined the $\mathrm{p} K$ by anaerobic spectrophotometric titration, and estimate the $\mathrm{p} K$ to be $7.0 \pm 0.1$ from such experiments (fig. 3 ).

It should also be noted that both the oxidized and reduced forms of deazariboflavin are fluorescent, with clearly defined characteristics. The oxidized form is strongly fluorescent with an emission maximum at $457 \mathrm{~nm}$. It has approximately 5 times the fluorescence intensity of the dihydrodeazariboflavin anion, whose emission maxium is at $395 \mathrm{~nm}$. By contrast the neutral dihydrodeazariboflavin is more weakly fluorescent, with an emission maximum at $410 \mathrm{~nm}$ (Fig. 4). It is interesting to compare these characteristics with normal 1,5-dihydroflavins, which have only recently been recognized as fluorescent [19]. In the latter case it is necessary to immobilize the reduced flavin, either by very low temperature in the free form, or by binding to specific apoproteins, in order for the fluorescence to be readily detectable.

Deazaflavins have been used to replace the natural flavin coenzymes with several different apoenzymes [1-8]. In most cases the resulting deazaflavin 
enzymes can be reduced by the specific substrates of the enzyme, albeit at rates of the order of $10^{-2}-10^{-4}$ that of the native enzyme. In some cases specific hydrogen transfer from the substrate to the resulting dihydrodeazaflavin has been demonstrated. Such findings would seem to implicate formally a hydride ion tranfer from substrate to deazaflavin, and by extrapolation implies a similar mechanism in normal flavoenzyme catalysis. However, as pointed out by Fenner et al. [20] and by Blankenhorn [18] the deazaflavin redox system has many of the characteristics of the pyridine nucleotide redox system, which is well known to accept reducing equivalents via a formally hydride ion transfer mechanism. Hence the results obtained from studies with deazaflavin enzymes may not be unequivocally extrapolated to the native enzymes. Being sufficiently similar in structure to the native flavins the deazaflavins may bind to specific apoproteins, but by virtue of their chemical properties, may accept reducing equivalents by a different mechanism than that applying with the native enzymes. In this respect it is interesting to consider the enzyme lactate oxidase, which has recently been shown to be reduced by substrate via a transient $\mathrm{N}(5)$-substituted covalent intermediate [21]. If a similar intermediate were formed in the case of the deazaflavin enzyme, the intermediate would be expected to be much more stable. However, no evidence for such a covalent intermediate could be obtained (Massey, V., unpublished results and ref. 13). The possibility that deazaflavins are better nicotinamide models than flavin models may account for the much slower reduction rates so far observed for deazaflavin enzymes than for the native enzymes. While the redox potential of the deazaflavin couple is lower than that of normal flavins, the difference per se would not account satisfactorily for the big differences observed, unless, in all cases, binding to the apoprotein resulted in a greater differential of the redox potential than that found for the free systems.

Another property in which the reduced deazaflavins are much more similar to dihydronicotinamides than to dihydroflavins is their unreactivity toward $\mathrm{O}_{2}$. Not surprisingly this property is retained on binding to specific apoenzymes, accounting for the lack of any catalytic activity with deazasubstituted D-amino acid oxidase, glucose oxidase, lactate oxidase or xanthine oxidase. While the dark reaction of reduced deazaflavins is extremely slow, with $t_{1 / 2}$ values of the order of $40 \mathrm{~h}$, [13] this process is markedly accelerated by visible light and shows autocatalysis (Fig. 1). The photooxidation rate is maximal at approximately $50 \%$ reoxidation, suggesting that an excited state of the oxidized form is responsible. Similarly light stimulated reoxidation is observed in the reaction of reduced deazaflavins with normal flavins and flavoproteins. The nature of these reactions is under active investigation. Whatever the mechanism of the light reaction, it should be emphasized that for valid interpretation of the reactivity of dihydrodeazaflavins, light should be strictly excluded.

\section{Acknowledgements}

This work was supported by U.S. Public Health Service Grant (GM11106). We are indebted to Drs. Peter Hemmerich, H. Fenner and H.J. Duchstein for 
the gifts of lumiflavin 3-acetate, deazariboflavin, and 1,5-dihydrodeazariboflavin, and for communicating the results of unpublished experiments.

\section{References}

1 Edmonson, D.E., Barman, B. and Tollin, G. (1972) Biochemistry 11, 1133-1138

2 Jorns, M.S. and Hersh, L.B. (1975) J. Biol. Chem. 250, 3620-3628

3 Hersh, L.B. and Jorns, M.S. (1975) J. Biol. Chem. 250, 8728-8734

4 Fisher, J., Spencer, R. and Walsh, C. (1976) Biochemistry 15, 1054-1064

5 Hersh, L.B., Jorns, M.S., Peterson, J. and Currie, B. (1976) J. Am. Chem. Soc., 98, 865-867

6 Averill, B.A., Schonbrunn, A., Ables, R.H., Weinstock, L.T., Cheng, C.C., Fisher, J., Spencer, R. and Walsh, C. (1975) J. Biol. Chem. 250, 1603-1605

7 Abramovitz, A. and Massey, V. (1976) J. Biol. Chem. 251, 5327-5336

8 Cromartie, T.H. and Walsh, C.T. (1976) J. Biol. Chem. 251, 329-333

9 Janda, M. and Hemmerich, P. (1976) Angew. Chem., in the press

10 Casola, L., Brumby, P.E. and Massey, V. (1966) J. Biol. Chem. 241, 4977-4984

11 Guengerich, F.P., Ballou, D.P. and Coon, M.J. (1975) J. Biol. Chem. 250, 7405-7414

12 Mayhew, S.G., Foust, G.P. and Massaey, V. (1969) J. Biol. Chem, 244, 803-810

13 Spencer, R., Fisher, J. and Walsh, C. (1976) Biochemistry 15, 1043-1053

14 Fisher, J., Walsh, C. (1974) J. Am. Chem. Soc. 96, 4345-4346

15 Draper, R.D. and Ingraham, L.L. (1968) Arch. Biochem. Biophys. 125, 802-808

16 Müller, F. and Massey, V. (1968) J. Biol. Chem. 244, 4007-4016

17 Blankenhorn, G. (1975) Biochemistry 14, 3172-3176

18 Blankenhorn, G., E. J. Biochem, in the press

19 Ghisla, S., Massey, V., Lhoste, J. and Mayhew, S.G. (1974) Biochemistry 13, 589-597

20 Fenner, H., Roessler, H.H., Duchstein, H.J. and Hemmerich, P. (1976) in Flavins and Flavoproteins (Singer, T.P., ed.), pp. 343-348, Elsevier Scientific Publishing Co., Amsterdam

21 Massey, V. and Ghisla, S. (1975) Proceedings of the 10th FEBS Meeting, 145-158 